\title{
The Subjective Well-Being of Malaysian School Children: Grade Level, Gender and Ethnicity
}

\author{
Mitchell Clark1,2, H. S. Amar-Singh ${ }^{3,4}$, Lina Hashim4 \\ ${ }^{1}$ Department of Psychology, Mount Royal University, Calgary, Canada \\ ${ }^{2}$ Center for Child Well-Being, Mount Royal University, Calgary, Canada \\ ${ }^{3}$ Department of Pediatrics, Hospital Raja Permaisuri Bainun, Ipoh, Malaysia \\ ${ }^{4}$ Clinical Research Centre, Hospital Raja Permaisuri Bainun, Ipoh, Malaysia \\ Email: mclark@mtroyal.ca
}

Received 8 May 2014; revised 2 June 2014; accepted 27 July 2014

Copyright (C) 2014 by authors and Scientific Research Publishing Inc.

This work is licensed under the Creative Commons Attribution International License (CC BY).

http://creativecommons.org/licenses/by/4.0/

(c) (i) Open Access

\begin{abstract}
The present study explores the subjective well-being of Malaysian children between 12 and 14 years of age. These children are beginning the transition from childhood to adulthood. They are confronted by a range of social and developmental influences that impact their self concept, self esteem, independence skills and their sense of their personal well-being. Responses on the Personal Wellbeing Index (School Children) were collected from over a thousand children in Form 1 and Form 2 grade levels drawn from a sample of ten schools in Ipoh, Malaysia. The results for the sample as a whole range from the lowest average score in "happiness with life achievement" at 68.1 up to a score of 80.7 on the "personal relationships" domain out of a total possible score of 100. Significant differences between the male and female participants were noted with males rating their subjective well-being as higher than the ratings by females on their "satisfaction with life as a whole" as well as their happiness with "personal safety". The younger students (Form 1 gradelevel) rated their happiness as significantly higher on the majority of life domains as compared to Form 2 students. There was also a significant difference between the students attending Chinese schools and those attending non-Chinese "National" schools. While those attending Chinese schools rated themselves substantially higher in regard to their happiness with "achievement in life", those in the other schools rated themselves higher on most of the other domains as well as significantly higher on "satisfaction with life as a whole". The strongest associations with "life as a whole" included "standard of living", "personal safety" and "future security".
\end{abstract}

\section{Keywords}

Malaysia, Child Well-Being, Personal Wellbeing Index, Quality of Life, Subjective Well-Being, 


\section{Adolescents, School-Children, Gender, Ethnicity}

\section{Introduction}

This article describes a survey of the subjective quality of life (QoL) of students from 12 to 14 years of age living in Ipoh, Malaysia. Ipoh is the capital of the state of Perak and is the third largest city in Malaysia with a population of more than 700,000 (Central Intelligence Agency, 2014). Malaysia is a vibrant and complex country characterized by rapid growth and economic progress.

Within the past decade Malaysia has emerged from developing country status and is now considered a middle income country. This standing is evidenced by improvements in indicators such as life expectancy at birth (currently estimated at 74.52 years) and the infant mortality rate (now about 13.69 per 1000) (Central Intelligence Agency, 2014). It has transformed from an economy based on the production raw materials into a diversified economy that includes clothing, high technology industries, medical technology, and pharmaceuticals. Malaysia is a vibrant country with a relatively young population (median age is 24.9 years with $31.4 \%$ of the population under 15 years of age (Asia-Pacific Development Center on Disability, 2009).

Malaysia has an ethnically diverse population. Over sixty percent (67.4\%) of the population of 30 million are Malay. The other ethnic groups include Chinese (24.6\%), Indian (7.3\%) and other groups (0.7\%)) (Department of Statistics Malaysia, 2014). This diversity is reflected in the range of religious groups with recent estimates indicating the Muslims make up 61.3\% of the population while, Buddhists are 19.8\%, Christians, 9.2\%, and Hindus, 6.3\%. Those devoted to Confucianism, Taoism, other traditional Chinese religions make up 1.3\%, while $1.2 \%$ are of unknown or no religion (Central Intelligence Agency, 2014).

\subsection{Child Well-Being}

How children view their quality of life is of course a major concern of parents. It is also of interest, or should be, to many organizations including NGO's and various government departments. While this construct is of great importance, definitions and methods of measuring of child well-being (CWB) vary widely. Children at 12 to 14 years of age are beginning the transition from childhood to adulthood. It is a period marked by a series of important physical, psychological and social changes that can impact their subjective view of their quality of life within various life domains.

While most children emerge from this transition without the behavior problems and emotional difficulties previously attributed to this period, the biological and cognitive changes they must negotiate do impact their social-emotional well-being and identity development (a major developmental task during adolescence). During this stage, building self concept, self esteem, and independence skills are all affected by a range of factors including parenting style, peers, their school, their community, and larger contextual variables such as culture and historical period (Berk, 2005).

In their review of relevant literature, Goldbeck et al. (2007) note that there is limited and/or inconsistent data on differences between the genders or between age groups during adolescence. Previous studies indicated a reduction in life satisfaction during adolescence or no difference. There was also limited support for a greater decrease in QoL among girls than among boys. In their study Goldbeck et al. (2007) found that, among adolescents between 11 and16 years, girls rated their general and health-related life satisfaction as lower than boys. In both genders and across nearly all life domains, there was a significant decrease in general and health-related life satisfaction.

Reviews of previous research of subjective well-being (SWB) have resulted in a theory of homeostasis (Cummins et al., 2002; Cummins, 2003). In general and based on the review of a substantial amount of research, it appears that most people indicate that they are satisfied with their own life. The mean rating of subjective well-being across studies in western nations was approximately 75\%, (range 70\% - 80\%). There are however, results where the ratings are lower as in reported from Algeria, for example. Tiliouine et al. (2006) suggested that there are factors in that country that that are particularly difficult and undermine individuals' sense of satisfaction with life and their ability to maintain homeostasis. They note that these results might also be the result of a response bias. The possible impact of response bias was also discussed by Lau et al. (2005) in their analysis of 
data gathered in Hong Kong.

While cultural predispositions may impact ratings, associations between suicidal ideation (Park et al., 2005) and depression (Hawkins et al. 1992) and perceived quality of life among adolescents have been demonstrated. Monitoring the level of life satisfaction amongst adolescents both as a group and as individuals is a valuable practice. Results can identify the rates of psychological difficulties experienced by individuals and also suggest the need for social policy initiatives where ratings demonstrate an adolescent population's satisfaction with aspects of their lives is being undermined by social or other environmental concerns.

\subsection{Purpose of the Study}

The aim of this study is to benchmark the level of children's well-being among students attending schools in Ipoh, Malaysia. Specific objectives associated with this aim include:

- evaluating the adequacy of the Personal Wellbeing Index-School Children (PWI-SC) instrument for the purpose of establishing the SWB of school students in Malaysia.

- identifying the relative contributions of the seven domains of the PWI-SC to the structure of SWB in Malaysian school children.

- examining the results of the study for differences in SWB among Malaysian school children due to ethnicity, gender and grade/age level differences.

\section{Method}

\subsection{Participants}

Following the consent of the Perak State Department of Education, fifteen (15) schools were randomly selected from among the 40 government secondary schools in the IPOH area. Secondary schools that are either National Schools or Islamic Schools use the national language, Bahasa Malaysia, as the language of instruction. There are also Chinese Schools where Chinese in the language of instruction. While two different languages are used, the curriculum is consistent throughout the schools in Ipoh.

Students at "Form 1" and "Form 2" grade-levels (generally aged 12 - 14 years) within the ten schools were included in the study. Within the ten schools, notices were sent home with students requesting parents indicate whether or not they would allow their children to participate in this study. The students whose parents agreed to allow them to participate were then requested to indicate whether they wished to participate. The students were notified that, if they did participate, they could refuse to respond to any questions they did not feel comfortable answering and could discontinue their participation at any time if they wished to stop. Following the parent and student processes for acceptance of participation in the study, there were 1071 students included in the study. Out of this number, 28 students chose to not complete the entire questionnaire, and were excluded, leaving 1043 participants in the study.

Table 1 provides a description of the participants by gender, by grade-level or form, and by type of school. The percentage of students from Chinese schools (24.5\%) is consistent with the estimated percentage of population of ethnic Chinese proportion of the population of Malaysia.

Table 1. Participant Characteristics.
\begin{tabular}{ccc}
\hline \multicolumn{2}{|c}{ Demographic Variables } & Student Participants ( $\mathrm{n}=1043) \mathrm{n}(\%)$ \\
\hline \multirow{2}{*}{ Gender } & Male & $555(53.2)$ \\
& Female & $488(46.8)$ \\
School Grade & Form 1 & $538(51.6)$ \\
& Form 2 & $505(48.4)$ \\
Type of School & National & $727(69.7)$ \\
& Islamic & $60(5.8)$ \\
& Chinese & $256(24.5)$ \\
\hline
\end{tabular}




\subsection{Instrument}

The Personal Wellbeing Index-School Children (PWI-SC) scale (Cummins and Lau, 2005) is one of a series of parallel forms of the Personal Wellbeing Index (PWI). All of the forms of the PWI measure subjective well-being (SWB). This scale evaluates how individuals perceive the quality of their life across seven domains: standard of living, personal health, achievement in life, personal relationships, personal safety, community connectedness, and future security; as well as the broader concept of "life as a whole". A Likert scale allows participants to indicate their evaluation of their persons SWB in each of the seven domains as well as "life as a whole" on a scale from 0 to 10 points,

The PWI has been demonstrated to be a statistically stable, and a valid instrument, as part of the Australian Unity Wellbeing Index since 2001 (Cummins and Lau, 2005). An additional advantage of this scale has been its development for use in cross-cultural situations (Lau et al., 2005; Tiliouine et al., 2006) and has been demonstrated to be a reliable and valid measure of SWB in these diverse settings.

\subsection{Translations}

For the purposes of this study Chinese (Mandarin) and Bahasa Malaysia translations of the PWI-SC were needed for the study. Parent and student release forms were also translated into Bahasa Malaysia and Mandarin. The Bahasa Malaysia translation was completed by Abdul Rahman Bin Mandali, Educational Services Officer (Pegawai Perkhidmatan Pendidikan) who has a Master of Arts, Translation Studies from the Universiti Sains Malaysia. The Chinese translation was completed by Dr Wong Woan Ying and Dr Chin Saw Sia, both of whom are pediatricians. As English is also spoken by some living in Ipoh and taught in the schools, the English version of the PWI-SC was also available for use.

\subsection{Procedure}

Following the random selection of 15 schools from among the 40 government schools in the Ipoh area, the selected schools were contacted and the proposed study was outlined to the principal (head master) who indicated whether the school would participate in the study. As one school refused to participate, student participants were recruited from 10 of the 14 remaining selected schools. As noted in Table 1 there were students from various categories of schools. Within the sample of 10 schools from which data was gathered, seven were described as national schools, one was identified as an Islamic school and two were Chinese schools. The numbers of students from each of these three categories of schools that participated in the study are noted in Table 1.

Three (3) Form 1 and three Form 2 classes were randomly selected from among the Form 1 and Form 2 classes in each school. The students in the selected classes were given a notice to take home to their parents/guardians. The notices described the research and requested that a parent or guardian sign the consent form if they wished to allow their child to participate in the study. Those students whose parents consented to their involvement were then requested to sign a consent form indicating their willingness to participate given that their privacy would be maintained and that they could choose to not answer specific questions or discontinue their involvement at any time. Those students who provided a signed consent form were then requested to complete the PWI-SC Scale.

\subsection{Data Analysis}

Those students that completed all of the questions in the PWI-SC were included in the sample.

In order to allow greater convenience in the comparison of results of this study to data collected in other SWB studies, the Likert scale data was converted to its equivalent unit on a 0 to 100 scale. For the 0 to 10 Likert scale this change only required moving the decimal point one place to the right (e.g., a score of 3 would become a score of 30). The scores on a 0 to 100 scale could also be presented as a percentage of the scale maximum. The process for converting Likert scales to a 0 to 100 distribution is outlined by Lau et al. (2005).

Data was analyzed using SPSS 13.0 for Windows. Descriptive statistics were used to summarize data on participant characteristics and to describe the participant responses on the PWI-SC scale. Cronbach's $\alpha$ (alpha) was computed for inter-domain and item total scores to provide an indication of the internal consistency of the PWI-SC. The bivariate correlation coefficients between the items for each of the seven domains, seven item totals, and "life as a whole" scores were calculated to indicate the level of association between these variables. A 
factor analysis was completed to determine the patterns of relationships among these variables. $\mathrm{T}$ scores were then calculated to allow comparisons between various groups of participants represented in the sample of school students.

\section{Results}

\subsection{Happiness Ratings on the PWI-SC}

The means and standard deviations of the ratings on each of the domains and "life as a whole" item are presented in Table 2.

The results range from the lowest on happiness with life achievement at 68.1 up to a score of 80.7 on the personal relationships domain. The happiness with future security item is relatively low at 71.0 while the other four domains (standard of living, health, personal safety and feeling part of the community) cluster between 75.4 and 79.7. The mean rating for the happiness with life as a whole was 75.3 .

\subsection{Internal Consistency}

The Cronbach $\alpha$ coefficient was calculated providing a value of 0.797 . This result indicates an adequate level of internal reliability and is consistent with previous calculations using PWI data from other countries (Lau, Cummins, \& McPherson, 2005; Tiliouine, Cummins, \& Davern, 2006).

\subsection{Domain Inter-Correlations}

Correlation coefficients describing the associations among the seven domains are presented in Table 3.

\section{Table 2. Happiness ratings on the PWI (school children).}

\begin{tabular}{lc}
\hline \multicolumn{1}{c}{ PWI-School Children Items } & Form 1 and Form 2 students in Ipoh schools (n = 1143) Mean (SD) \\
\hline Happiness with Standard of Living & $75.4(19.95)$ \\
Happiness with Health & $77.1(20.72)$ \\
Happiness with Achievement in Life & $68.1(22.97)$ \\
Happiness with Personal Relationships & $80.7(20.30)$ \\
Happiness with Personal Safety & $76.5(20.17)$ \\
Happiness with Feeling Part of the Community & $79.7(20.48)$ \\
Happiness with Future Security & $71.0(21.30)$ \\
Satisfaction with Life as a Whole & $75.3(18.67)$ \\
\hline
\end{tabular}

Table 3. Inter-domain correlations, and item-total and "life as a whole" correlations for the PWI (school children).

\begin{tabular}{|c|c|c|c|c|c|c|c|c|c|}
\hline PWI-School Children Domains & Stand & Hlth & Ach & Rel & Safe & Comm & Sec & Total & Life \\
\hline Happiness with Standard of Living & 1.000 & 0.27 & 0.29 & 0.32 & 0.38 & 0.32 & 0.38 & 0.66 & 0.53 \\
\hline Happiness with Health & 0.27 & 1.000 & 0.24 & 0.27 & 0.38 & 0.20 & 0.32 & 0.60 & 0.35 \\
\hline Happiness with Achievement in Life & 0.29 & 0.24 & 1.000 & 0.20 & 0.25 & 0.13 & 0.28 & 0.56 & 0.36 \\
\hline Happiness with Personal Relationships & 0.32 & 0.27 & 0.20 & 1.000 & 0.38 & 0.33 & 0.31 & 0.63 & 0.39 \\
\hline Happiness with Personal Safety & 0.38 & 0.38 & 0.25 & 0.38 & 1.000 & 0.31 & 0.41 & 0.70 & 0.46 \\
\hline Happiness with Feeling Part of the Community & 0.32 & 0.20 & 0.13 & 0.33 & 0.31 & 1.000 & 0.34 & 0.59 & 0.30 \\
\hline Happiness with Future Security & 0.38 & 0.32 & 0.28 & 0.31 & 0.41 & 0.34 & 1.000 & 0.69 & 0.43 \\
\hline Total for All Domains & 0.66 & 0.61 & 0.60 & 0.63 & 0.70 & 0.59 & 0.69 & 1.000 & 0.63 \\
\hline Happiness with Life as a Whole & 0.53 & 0.35 & 0.36 & 0.39 & 0.46 & 0.30 & 0.43 & 0.63 & 1.000 \\
\hline
\end{tabular}

Key: Stand—Standard of living, Hlth—Health, Ach-Life achievement, Re—Personal relationships, Safe-Personal safety, Comm—Feeling part of the community, Sec-Future security, Total-Total for all domains, Life-Happiness with life as a whole. 
All of the inter-correlations between the seven domains were statistically significant at the 0.001 level. The lowest correlation was 0.13 between the "Feeling part of the community" and the "Life achievement" items. Results ranged up to a high of 0.41 between the "Future security" and "Personal safety" items.

\subsection{Correlations: Domains with Total Score and Domains with "Life as a Whole"}

The correlations between the total score for the PWI-SC and "Life as a whole", and the relationships between these two variables and the seven domains are also shown in Table 3. Again, all of these correlations were significant at the 0.001 level.

"Personal safety" and "future security" were most strongly correlated with the total score at 0.70 and 0.69 respectively. The "Achievement in life" item was at the low end of the correlations between the total score and the domains at 0.56 .

Among the correlations between "Life as a whole" and the seven domains, "Standard of living" demonstrated the strongest relationship at 0.53 . The lowest correlation was 0.30 between total score for "Feeling part of the community".

\subsection{Factor Analysis}

In order to evaluate the adequacy of sampling for the conduct of a principal component analysis, a Kaiser-MeyerOlkin Measure of Sampling Adequacy (KMO) was conducted as well as a Bartlett's Test of Sphericity. The KMO result was 0.84 which supported proceeding with a factor analysis. Further, the Bartlett's test of Sphericity result was significant at the 0.001 level, indicating a strong relationship between the domains and that proceeding with a factor analysis was appropriate.

A principal component factor analysis was completed using the student responses on the PWI-SC. The Kaiser criterion was employed for determining the number of components identified in this analysis. Based on this criterion, one factor with an eigen value greater than 1 (2.84) was extracted, accounting for $40.57 \%$ of the variance (Table 4). A Cattell scree test confirmed the extraction of one factor from the SWB domains. The emergence of one factor from PWI data is consistent with results from other studies (Lau, Cummins, \& McPherson, 2005; Tiliouine, Cummins, \& Davern, 2006). In a diverse group of three countries, Australia, Hong Kong and Algeria, all seven domains loaded into one factor on the PWI.

In the current study, across the seven items on the PWI-SC, the data produced loadings from 0.50 for "achievement in life" up to 0.70 for "future security" and 0.73 for "personal safety". As all of the component loadings were 0.50 or above, each of the seven indicators included a moderate to a relatively high level of the variance explained by the SWB factor. As noted above, this factor analysis is consistent with results from previous studies and the high component loadings indicate that PWI-SC demonstrates convergent validity.

Table 4. Factor analysis for the PWI-SC items.

\begin{tabular}{cc}
\hline PWI-School Children Items & Factor Loadings of One Factor \\
\hline Happiness with & 0.68 \\
Standard of Living & 0.60 \\
Health & 0.50 \\
Achievement in Life & 0.64 \\
Personal Relationships & 0.73 \\
Personal Safety & 0.57 \\
Feeling part of the Community & 0.70 \\
Future Security & 2.84 \\
Eigen Value & 40.57 \\
\hline
\end{tabular}




\subsection{Well-Being and Gender}

In order to examine differences between males and female students, $t$ tests were conducted to determine whether there were significant differences between the mean score for each gender on the seven domains as well as student ratings of happiness with life as a whole. The results are provided in Table 5.

Male students rated their happiness as higher than females on the "standard of living”, "health", "feeling part of the community" and "personal safety" domains, and with "life as a whole". Only on the standard of living domain and the "life as a whole" variable were the males significantly higher than the females (at the 0.01 level of significance). Female students indicated they were happier than males on the "achievement in life" and "personal relationships" domains. Neither of these differences was statistically significant however. Males and females provided equivalent happiness ratings on the "future security" domain.

\subsection{Well-Being and Grade-Level}

The mean happiness ratings by students in the Form 1 grade-level were compared with the mean ratings provided by students in Form 2. Table 6 provides the t-test results for each of the domains and "life as a whole".

The comparison between the two Forms (grade levels) is quite striking. On all of the variables the mean happiness ratings of the Form 1 students are higher than those provided by Form 2 students. Six of the eight results reached statistical significance. The higher ratings by form 1 students on their "standard of living”, "achievement in life" and their "future security" were significant at the 0.001 level. Their higher ratings on their happiness with their "health", "personal safety", and "feeling part of the community" were statistically significant at the 0.05 level.

Table 5. Well-being and gender.

\begin{tabular}{|c|c|c|c|}
\hline PWI-School Children Items & Males $(n=555)$ Mean $(S D)$ & Females $(\mathrm{n}=488)$ Mean (SD) & t scores \\
\hline Happiness with Standard of Living & $76.3(20.3)$ & $74.3(19.5)$ & 1.59 \\
\hline Happiness with Health & $77.9(20.8)$ & $76.2(20.6)$ & 1.31 \\
\hline Happiness with Achievement in Life & $66.9(22.7)$ & $69.3(23.2)$ & -1.70 \\
\hline Happiness with Personal Relationships & $80.3(20.8)$ & $81.3(19.7)$ & -0.79 \\
\hline Happiness with Personal Safety & $78.1(20.1)$ & $74.7(20.2)$ & $2.67 * *$ \\
\hline Happiness with Feeling part of the Community & $80.5(21.0)$ & $78.8(19.9)$ & 1.41 \\
\hline Happiness with Future Security & $71.0(22.3)$ & $71.0(20.1)$ & -0.041 \\
\hline Satisfaction with Life as a Whole & $76.8(18.7)$ & $73.6(18.5)$ & $2.69 * *$ \\
\hline
\end{tabular}

$* p<0.05 ; * * p<0.01$.

Table 6. Well-being and education grade-level.

\begin{tabular}{|c|c|c|c|}
\hline PWI-School Children Items & Form 1 Students $(\mathrm{n}=538)$ Mean (SD) & Form 2 Students $(\mathrm{n}=505)$ Mean (SD) & t scores \\
\hline Happiness with Standard of Living & $77.4(20.0)$ & $73.2(19.7)$ & $3.41^{* * *}$ \\
\hline Happiness with Health & $78.5(20.5)$ & $75.6(20.8)$ & $2.24^{*}$ \\
\hline Happiness with Achievement in Life & $70.7(22.6)$ & $65.2(23.0)$ & $3.93 * * *$ \\
\hline Happiness with Personal Relationships & $81.2(20.5)$ & $80.3(20.1)$ & 0.68 \\
\hline Happiness with Personal Safety & $77.8(20.1)$ & $75.2(20.2)$ & $2.05^{*}$ \\
\hline Happiness with Feeling Part of the Community & $81.1(19.9)$ & $78.2(21.0)$ & $2.24^{*}$ \\
\hline Happiness with Future Security & $73.5(21.0)$ & $68.4(21.4)$ & $3.87 * * *$ \\
\hline Satisfaction with Life as a Whole & $76.3(18.6)$ & $74.2(18.7)$ & 1.82 \\
\hline
\end{tabular}

${ }^{*} p<0.05 ;{ }^{* *} p<0.01 ;{ }^{* * *} p<0.001$. 


\subsection{Well-Being and Ethnicity}

T-tests were conducted to evaluate the differences in results between students attending Chinese schools and those students attending other schools that were not providing instruction using the Chinese language. The outcomes of this analysis are provided in Table 7.

There was a very different pattern in the results for students in the Chinese schools as compared to students in other schools selected for this study. The Chinese school students had lower ratings on all of the variables with one exception. A number of the differences were quite substantial. Students from the non-Chinese schools rated themselves as happier with "standard of living", "feeling part of the community" and their "future security" at the 0.001 level of significance. They were also significantly higher on the personal safety domain ( 0.05 level of significance) and on "life as a whole" (0.01 level of significance). The one area that the Chinese students provided a higher rating (over an 11 point difference in mean happiness rating) was in the area of "achievement in life”.

\section{Discussion}

The aim of this study was to provide a baseline the level of children's well-being among students attending schools in Ipoh, Malaysia. The results indicate that, in general, these children are happy with their "life as a whole" with an average of 75.3 out of 100 . This rating, along with the ratings of the level of happiness on the various domains will allow future comparisons to determine whether various societal and social policy changes are having an impact on the subjective well-being experienced by children in this age group.

Other future comparisons with this benchmark may also be of interest. For example, ratings of subjective well-being of children in various states of Malaysia may to evaluate the consequences for children of policy and economic discrepancies between regions. These ratings might also be used as a basis of caparison to the subjective well-being of children in other countries. Various assessments and comparisons of SWB can provide a barometer of how Malaysian children feel they are faring.

There were several specific objectives that prompted this study. It was hoped that this research would provide an opportunity to evaluate the adequacy of the PWI-SC as a measure of SWB of school students in Malaysia. The results of the factor analysis and the analysis of the internal consistency described above are reflective of the results found in previous studies (Lau et al., 2005; Tiliouine et al. 2006) and support the adequacy of this instrument as a useful approach to measuring SWB within this context.

Another of the specific outcomes sought in this study was a description of the relative contributions of the seven domains of the PWI to the structure of SWB in Malaysian school children. Table 3 outlines the associations of the domains with the students' ratings of their satisfaction with life as a whole. The strongest associations, as noted earlier, are seen for happiness with "standard of living" personal safety and future security. It is interesting that the focus seems to be on aspects of safety and security. As Malaysia continues on a course of economic development there may be changes in the relative weighting of the domains of SWB with an increased influence of the areas of personal and community connectedness and personal achievement. The relationship of the social and economic context to structure of SWB in these children could be clarified by future studies.

Table 7. Well-being and ethnicity.

\begin{tabular}{cccc}
\hline PWI-School Children Items & $\begin{array}{c}\text { Chinese Students ( } \mathrm{n}=256) \\
\text { Mean (SD) }\end{array}$ & $\begin{array}{c}\text { Non-Chinese Students (n=787) } \\
\text { Mean (SD) }\end{array}$ & $\begin{array}{c}\mathrm{t} \text { scores } \\
\text { Happiness with Standard of Living }\end{array}$ \\
Happiness with Health & $76.7(20.1)$ & $76.6(19.8)$ & $-3.39^{* * *}$ \\
Happiness with Achievement in Life & $76.5(20.9)$ & $77.4(21.1)$ & -0.95 \\
Happiness with Personal Relationships & $79.3(19.9)$ & $65.3(23.0)$ & $7.26^{* * *}$ \\
Happiness with Personal Safety & $73.9(21.1)$ & $81.2(20.4)$ & -1.29 \\
Happiness with Feeling Part of the Community & $73.7(23.4)$ & $77.4(19.8)$ & $-2.35^{*}$ \\
Happiness with Future Security & $67.3(20.1)$ & $81.7(19.0)$ & $-5.10^{* * *}$ \\
Satisfaction with Life as a Whole & $72.8(17.8)$ & $72.2(21.5)$ & $-3.34^{* * *}$ \\
\hline
\end{tabular}

${ }^{*} p<0.05 ; * * p<0.01$; *** $p<0.001$. 
The collection of data across different grade levels, across genders and across schools accommodating different ethnic groups, allowed comparison of the ratings of these different categories of students. The results of these comparisons are, in general consistent with previous studies. For example research suggests that the SWB gradually decreases during adolescence (Goldbeck et al., 2007; Ravens-Sieberer et al., 2007). An examination of Table 6 indicates that the students in Form 1 rate their SWB as significantly higher that students in Form 2 in all but one of the domains. While the Form 1 students are also higher in their rating of their satisfaction with "life as a whole", this difference is not significant. Based on the domain results there does appear to be drop in SWB amongst the typically older students as previous literature suggests.

The difference in the relative ratings of males and female students is less decisive. In this study females scored lower on the majority of domains, although the difference on the "personal safety" domain was the only one that was significant. It is important to note that the female students also scored significantly lower on their ratings of their "satisfaction with life as a whole".

The differences between students attending Chinese schools and those attending all of the other schools are quite striking. The Chinese students rate their SWB lower on all of the domains with one exception. These lower ratings are significantly different other than the lower rating for happiness with "personal relationships". The Chinese students also rate their "satisfaction with life as a whole" as significantly lower than the students attending non-Chinese schools. The one area which is rated higher by the Chinese students is their happiness with their "achievement in life". This difference is both statistically significant and substantial. The focus on achievement appears to be at the cost of these students SWB relative to the students in the non-Chinese schools. It would be of interest to see if this difference continues through adolescence and into adulthood. It would also be worthwhile to compare these results with the rates of SWB in other countries where there are Chinese and other ethnic minority groups.

\section{Conclusion}

This initial evaluation of the SWB of Malaysian children provides a variety of useful insights into the level and structure of their sense of their own quality of life. It also raises a number of issues in the comparison of these children related to age, gender and ethnicity. The reasons for these differences might be clarified and interventions to enhance the SWB of children in general, and of those groups that have relatively lower ratings might be developed. Certainly further research is suggested. Studies that examine well-being across a wider range of grade-levels would be helpful to confirm the indications from the study reported here. The collection of qualitative data that helps to identify the causes of group differences and point to possible supports is also suggested. Finally, studies of the SWB of children in various regions of Malaysia would be useful to determine if the quality of life of children is similar across the country or there are variations due to differing situations in various locations.

\section{Acknowledgements}

The researchers wish to extend their gratitude to the Department of Education for Perak for allowing the study to proceed. We also wish to thank to the head masters of the participating schools for their help and their support of this research. We are particularly grateful to the students in the classrooms selected for inclusion in the study as well as their teachers and parents. We also wish to thank Musnira Mustaffa and Juraini Hafida Samsani who acted as research assistants during the study and completed the data collection in the schools.

The authors are grateful to the Office of Research Services at Mount Royal University, Calgary, Canada, for research grant that allowed the completion of this study of Child Well-Being. We also acknowledge the advice and assistance provided by the Clinical Research Centre, Hospital Raja Permaisuri Bainun, Ipoh, Malaysia.

\section{References}

Asia-Pacific Development Center on Disability (2009). Malaysia.

http://www.apcdfoundation.org/?q=content/malaysia

Berk, L. E. (2005). Infants, Children and Adolescents (5th ed.). Boston: Allyn and Bacon.

Central Intelligence Agency (2014). The World Fact Book: Malaysia. www.cia.gov/library/publications/the-world-factbook/geos/my.html 
Cummins, R. A. (2003). Normative Life Satisfaction: Measurement Issues and a Homeostatic Model. Social Indicators Research, 64, 225-256. http://dx.doi.org/10.1023/A:1024712527648

Cummins, R. A., Eckersley, R., Pallant, J., Van Vugt, J., \& Misajon, R. (2003). Developing a National Index of Subjective Wellbeing: The Australian Unity Wellbeing Index. Social Indicators Research, 64, 159-190. http://dx.doi.org/10.1023/A:1024704320683

Cummins, R. A., Gullone, E, \& Lau, A. L. D. (2002). A Model of Subjective Well Being Homeostasis: The Role of Personality. In E. Gullone \& R. A. Cummins (Eds.), The Universality of Subjective Wellbeing Indicators: Social Indicators Research Series (pp. 7-46). Dordrecht: Kluwer.

Cummins, R. A., \& Lau, A. L. D. (2005). Personal Well-Being Index-School Children (PWI-SC) Manual (3rd ed.). Melbourne: Deakin University.

Department of Statistics Malaysia (2014). http://www.statistics.gov.my/portal/index.php?option=com_content\&id=1215

Hawkins, W. E., Hawkins, M. J., \& Seeley, J. (1992). Stress, Health-Related Behavior and Quality of Life on Depressive Symptomatology in a Sample of Adolescents. Psychological Reports, 71, 183-186. http://dx.doi.org/10.2466/pr0.1992.71.1.183

Goldbeck, L., Schmitz, T. G., Besier, T., Herschbach, P., \& Henrich, G. (2007). Life Satisfaction Decreases During Adolescence. Quality of Life Research, 16, 969-979. http://dx.doi.org/10.1007/s11136-007-9205-5

Lau, A. L. D., Cummins, R. A., \& McPherson, W. (2005). An Investigation into the Cross-Cultural Equivalence of the Personal Wellbeing Index. Social Indicators Research, 72, 403-430. http://dx.doi.org/10.1007/s11205-004-0561-z

Park, H. S., Koo, H. Y., \& Schepp, K. G. (2005). Predictors of Suicidal Ideation for Adolescents by Gender. Taehan Kanho Hakhoe Chi, 35, 1433-1442.

Ravens-Sieberer, U., Auquier, P., Erhart M., Gosch, A., Rajmil, L., Bruil, J.,Power, M., Duer, W., Cloetta, B., Czemy, L., Mazur, J., Czimbalmos, A., Tountas, Y., Hagquist, C., \& Kilroe, J. (2007). The KIDSCREEN-27 Quality of Life Measure for Children and Adolescents: Psychometric Results from a Cross-Cultural Survey in 13 European Countries. Quality of Life Research, 16, 1347-1356. http://dx.doi.org/10.1007/s11136-007-9240-2

Tiliouine, H., Cummins, R. A., \& Davern, M. (2006). Measuring Wellbeing in Developing Countries: The Case of Algeria, Social Indicators Research, 75, 1-30. http://dx.doi.org/10.1007/s11205-004-2012-2 
Scientific Research Publishing (SCIRP) is one of the largest Open Access journal publishers. It is currently publishing more than 200 open access, online, peer-reviewed journals covering a wide range of academic disciplines. SCIRP serves the worldwide academic communities and contributes to the progress and application of science with its publication.

Other selected journals from SCIRP are listed as below. Submit your manuscript to us via either submit@scirp.org or Online Submission Portal.
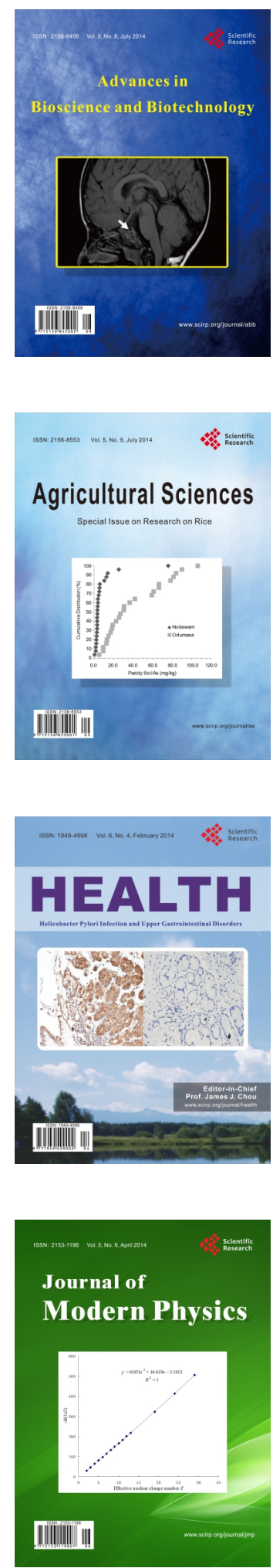
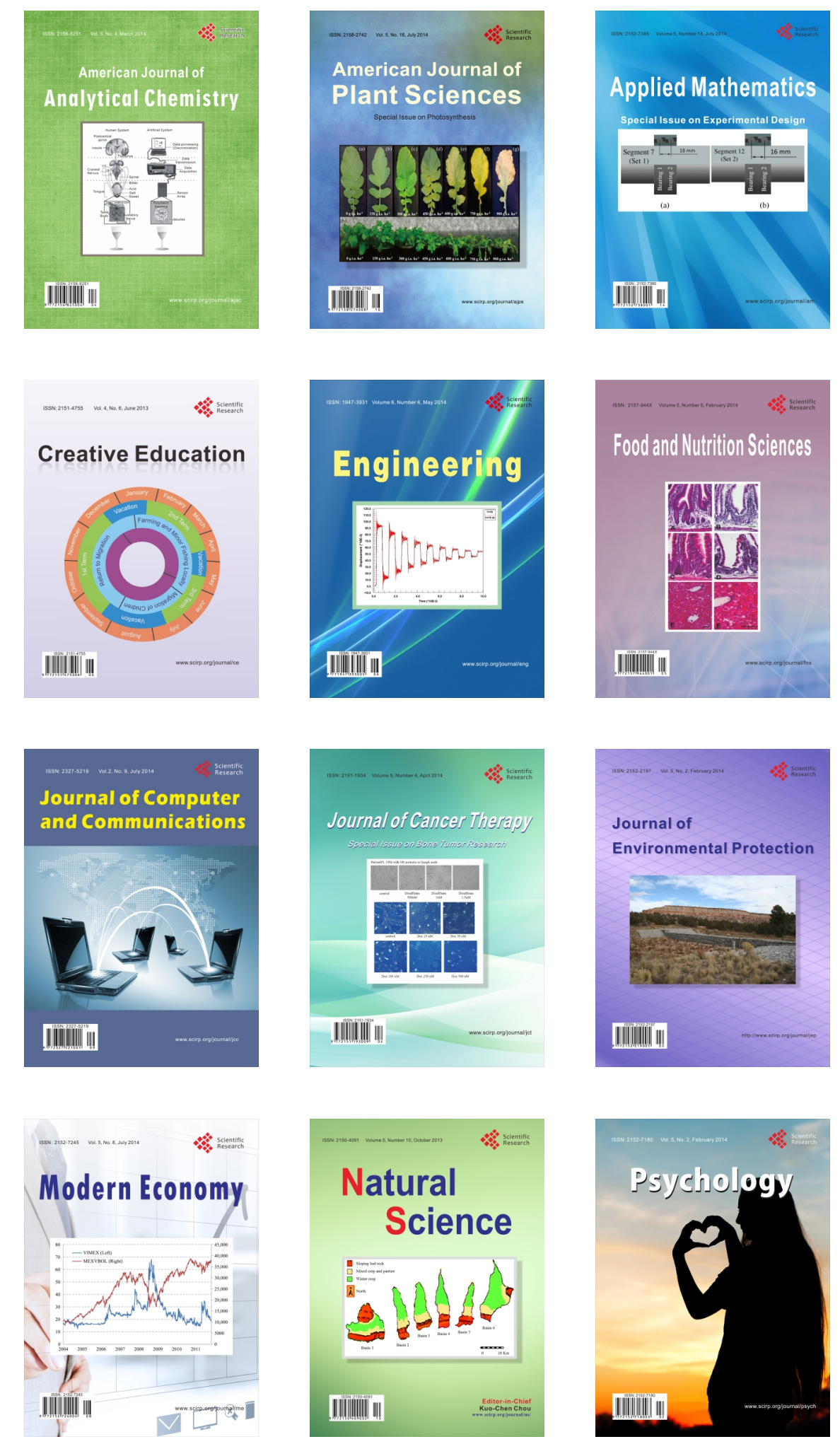